\title{
PRODUÇÃO DE ALFACE AMERICANA EM FUNÇÃO DA ADUBAÇÃ̃o NITROGENADA NAS CONDIÇÕES DE PRIMAVERA EM JATAÍ-GO
}

\author{
José Hortêncio Mota ${ }^{1}$, Caio César Ramos da Silva ${ }^{1}$, Jony Eishi Yuri², Geraldo Milanez de \\ Resende $^{2}$

\footnotetext{
${ }^{1}$ Universidade Federal de Goiás -Regional Jataí, Jataí - GO, E-mail: hortenciomota@terra.com.br, caioramos16@ hotmail.com ${ }^{2}$ Embrapa Semiárido, Petrolina - PE, E-mail: jony.yuri@embrapa.br, geraldo.milanez@embrapa.br
}

\section{RESUMO}

O objetivo deste estudo foi avaliar o efeito da aplicação de duas fontes de nitrogênio (ureia e NovaTec $®$ ) na produção da alface americana, nas condições de primavera, em Jataí-GO. Foram utilizadas mudas da cultivar de alface americana Lucy Brown, sendo avaliadas as características: massa fresca total e comercial, número de folhas, diâmetro e comprimento de caule. Verificou-se que todas as características avaliadas foram influenciadas pela adubação com ureia enquanto que $\mathrm{NovaTec}{ }^{\circledR}$ influenciou apenas o comprimento de caule e as massas fresca total e comercial. A dose de $61 \mathrm{~kg} \mathrm{ha}^{-1}$ de ureia em cobertura, proporcionou a maior massa fresca comercial.

Palavras-chave: Lactuca sativa, ureia, fertilização

\section{YIELD OF CRISPHEAD LETTUCE IN FUNCTION OF NITROGEN APPLICATION, IN SPRING SEASON, IN JATAÍ, STATE OF GOIÁS, BRAZIL}

\section{ABSTRACT}

The aim of this study was to evaluate the effects of two nitrogen sources of fertilization (urea and NovaTec ${ }^{\circledR}$ ) on the yield of crisphead lettuce, under spring conditions, in Jataí, State of Goiás, Brazil. Seedlings of crisphead lettuce cv. Lucy Brown were used. The evaluated characteristics were: total and commercial fresh mass, number of leaves, length and diameter of the stem. One verified that all the evaluated characteristics were influenced by urea while NovaTec ${ }^{\circledR}$ influenced only the length of the stem and total and commercial fresh mass. The dose of $61 \mathrm{~kg} \mathrm{ha}^{-1}$ of urea in coverage, resulted in the highest commercial fresh mass.

Keywords: Lactuca sativa, urea, fertilization

\section{INTRODUÇÃO}

A alface (Lactuca sativa L.), planta herbácea da família Asteraceae, é a hortaliça folhosa mais consumida no Brasil e está entre as hortaliças folhosas mais cultivadas e importantes do mundo (FERNANDES \& MARTINS, 1999). Originária do Sul da 


\section{PRODUÇÃO DE ALFACE AMERICANA EM FUNÇÃO DA ADUBAÇÃO NITROGENADA NAS \\ CONDIÇÕES DE PRIMAVERA EM JATAÍ-GO}

Europa e da Ásia Ocidental, atualmente está difundida por todo o mundo, sendo cultivada em quase todos os países. É consumida de in natura, sendo boa fonte de vitaminas e sais minerais e devido ao baixo teor de calorias, recomendada para dietas alimentares ricas em fibras (FILGUEIRA, 2008).

Um dos fatores importantes para o sucesso da cultura da alface é a adubação. Trata-se de uma cultura bastante exigente em nutrientes e, em especial, o nitrogênio. Devido a cultura ser composta basicamente de folhas, a mesma responde bem ao fornecimento de nitrogênio, nutriente que requer um manejo especial quanto à adubação, por ser de fácil lixiviação e pelo fato da alface absorver maior quantidade na fase final do ciclo. A sua deficiência retarda o crescimento da planta (ALMEIDA et al., 2011), induz à má formação da cabeça e ao amarelecimento das folhas mais velhas (GOTO et al., 2001).

Para a cultura da alface, o nitrogênio é o segundo nutriente mais extraído (BENINNI et al., 2005). Doses adequadas de nitrogênio favorecem o crescimento vegetativo, o acúmulo de massa e aumento da área foliar, entretanto, o excesso pode ocasionar uma série de problemas, entre as quais, perda de qualidade do produto (MALAVOLTA, 2006; FILGUEIRA, 2008).
As principais fontes de fertilizantes nitrogenados utilizados para adubação da cultura são: ureia, sulfato de amônio, nitrato de potássio, nitrato de amônio e salitre do Chile, não existindo concordância quanto à melhor fonte de nitrogênio para a espécie (CASTRO \& FERRAZ JUNIOR, 1998), uma vez que as perdas por lixiviação dessas fontes de $\mathrm{N}$ são muito acentuadas, variando em função do solo e do clima da região.

Atualmente, existem no mercado muitas fontes de nitrogênio disponíveis para o produtor, cada qual com suas particularidades e vantagens. Portanto, é necessário buscar um manejo adequado e racional dos nutrientes no seu ciclo produtivo, com objetivo de maximizar a produção e minimizar custos, proporcionando maior rentabilidade (LOPES, 2012).

Neste contexto, este estudo teve como objetivo avaliar o efeito da aplicação de doses de ureia e de NovaTec $\AA$ na produção da alface tipo americana, nas condições de primavera, em Jataí, região Sudoeste do Estado de Goiás.

\section{MATERIAL E MÉTODOS}

O experimento foi realizado no período de outubro a dezembro de 2013, em uma propriedade rural localizada no munícipio de Jataí-GO, nas coordenadas 
$17^{\circ} 53^{\prime} 08^{\prime \prime S}$ e $51^{\circ} 40^{\prime} 12^{\prime} \mathrm{O}$, a uma altitude média de 789 m. O clima da região, segundo a classificação de Köppen, é do tipo Aw tropical de savana e megatérmico com estações seca e chuvosa definidas. A temperatura média anual é de $23,7^{\circ} \mathrm{C}$ e a precipitação anual média de $1644,9 \mathrm{~mm}$ (INMET, 2013a).

Durante a condução do experimento, a precipitação total foi de $205,0 \mathrm{~mm}$ e a temperatura variou de 17,4 a $36,9^{\circ} \mathrm{C}$.

O solo da área experimental foi originalmente classificado como Latossolo Vermelho Distroférrico de textura argilosa (SANTOS et al., 2006). A amostragem do solo foi feita na camada de 0 a $20 \mathrm{~cm}$, sendo os resultados químicos encontrados: $\mathrm{pH}$ em $\mathrm{CaCl}^{2}=5,4 ; \mathrm{Ca}^{2+}=5,95$ cmolc dm${ }^{-3} ; \mathrm{Mg}^{2+}=$ 2,61 cmolc dm ${ }^{-3} ; \mathrm{Al}^{3+}=0,04$ cmolc dm ${ }^{-3} ; \mathrm{H}$ $+\mathrm{Al}=3,3$ cmolc $\mathrm{dm}^{-3} ; \mathrm{K}=582 \mathrm{mg} \mathrm{dm}^{-3}$; $\mathrm{P}(\mathrm{mel})=43,8 \mathrm{mg} \mathrm{dm}^{-3} ; \mathrm{S}=28,8 \mathrm{mg} \mathrm{dm}^{-3} ; \mathrm{B}=$ $0,34 \mathrm{mg} \mathrm{dm}^{-3} ; \mathrm{Cu}=8,5 \mathrm{mg} \mathrm{dm}^{-3} ; \mathrm{Fe}=17 \mathrm{mg}$ $\mathrm{dm}^{-3} ; \mathrm{Mn}=120,8 \mathrm{mg} \mathrm{dm}^{-3} ; \mathrm{Zn}=7,3 \mathrm{mg} \mathrm{dm}^{-3}$; $\mathrm{Na}=23,2 \mathrm{mg} \mathrm{dm}^{-3} ; \mathrm{CTC}=13,4$ cmolc dm$^{-3}$; $\mathrm{V} \%=41,4 \%$; M.O. $=44,8 \%$, argila $=410 \mathrm{~g}$ $\mathrm{dm}^{-3} ;$ silte $=75 \mathrm{~m}^{-3} \mathrm{mg} ;$ areia $=515 \mathrm{~g} \mathrm{dm}^{-3}$.

O delineamento experimental adotado foi em blocos casualizados em esquema fatorial $4 \times 4$ e quatro repetições. $\mathrm{O}$ primeiro fator foi representado por quatro doses de ureia $\left(0,40,80\right.$ e $\left.120 \mathrm{~kg} \mathrm{ha}^{-1}\right)$ e o segundo por quatro doses de $\operatorname{NovaTec}^{\circledR}(0$, 30, 60 e $90 \mathrm{~kg} \mathrm{ha}^{-1}$ ). Salienta-se que os fertilizantes foram aplicados na forma de adubação de cobertura, aos 25 dias após o transplantio. A ureia apresenta $45 \%$ de $\mathrm{N}$ na sua composição e o produto comercial NovaTec $^{\circledR}$ é um fertilizante que possui na sua formulação $24 \%$ de $\mathrm{N}, 5 \%$ de $\mathrm{P}_{2} \mathrm{O}_{5}$ e $5 \%$ de $\mathrm{K}_{2} \mathrm{O}$ e, segundo o fabricante, apresenta liberação lenta em contato com a água. Devido a essa característica tem a liberação gradativa de nitrogênio em forma de nitrato de amônia e apresenta uma película para diminuir a volatilização em altas temperaturas.

$\mathrm{O}$ experimento foi conduzido em canteiros, com parcelas de $1,8 \mathrm{~m}$ de comprimento e 1,0 m de largura, contendo 24 plantas de alface, com espaçamento de 0,30 $\mathrm{m}$ entre linhas e $0,25 \mathrm{~m}$ entre plantas, sendo dispostas em 4 linhas de 6 plantas. Considerou-se como parcela útil as 4 plantas centrais do canteiro. Esses canteiros foram previamente adubados com 10,0 $\mathrm{t} \mathrm{ha}^{-1} \mathrm{de}$ cama de frango.

A semeadura foi realizada utilizandose a cv. Lucy Brown, alface do tipo americana, em bandejas de isopor contendo 128 células e preenchidas com substrato comercial Bioplant ${ }^{\circledR}$. O transplantio das 
mudas para área experimental ocorreu 30 dias após a semeadura.

A irrigação utilizada foi por aspersão do tipo convencional, tendo um raio de $10 \mathrm{~m}$ de alcance. Os demais tratos culturais foram efetuados de acordo com as recomendações para a cultura. Realizou-se uma capina manual durante o ciclo de desenvolvimento da cultura, além de pulverizações preventivas contra pragas e doenças comuns à cultura.

A colheita foi realizada aos 60 dias após o transplantio, quando as plantas apresentavam padrão comercial, com cabeças bem compactas, sem indícios de florescimento e com máximo de desenvolvimento vegetativo (YURI et al., 2002). Após essa prática, foram realizadas as avaliações das seguintes características: massa fresca total (plantas cortadas rente ao solo e pesadas) e comercial (pesadas somente as cabeças comerciais, retirando-se as folhas externas danificadas); número de folhas (realizado o desfolhamento da planta e realizada a contagem de todas as folhas), diâmetro das cabeças comerciais e comprimento de caule.

Os dados coletados foram submetidos à análise de variância e regressão com base no modelo polinomial ao nível de $5 \%$ de probabilidade.

\section{RESULTADOS E DISCUSSÃO}

Observou-se pelo resumo da análise de variância (Tabela 1) que ocorreram diferenças significativas entre as doses de ureia para as variáveis número de folhas, diâmetro do caule, comprimento de caule e massa fresca total e comercial, enquanto que as doses de NovaTec $^{\circledR}$ apresentaram diferenças significativas apenas para as características comprimento de caule e massa fresca total e comercial. Houve interação significativa apenas para as variáveis diâmetro e comprimento de caule.

Os dados relativos ao número de folhas por planta apresentaram uma resposta quadrática em função das doses de ureia aplicadas, obtendo o valor máximo de 24 folhas planta ${ }^{-1}$ na dosagem de $63 \mathrm{~kg} \mathrm{ha}^{-1}$ (Figura 1a). A aplicação de doses de NovaTec $^{\circledR}$ não propiciou efeito significativo para as diferentes doses, sendo obtido um número médio de 23,1 folhas planta $^{-1}$ (Figura 1b). 

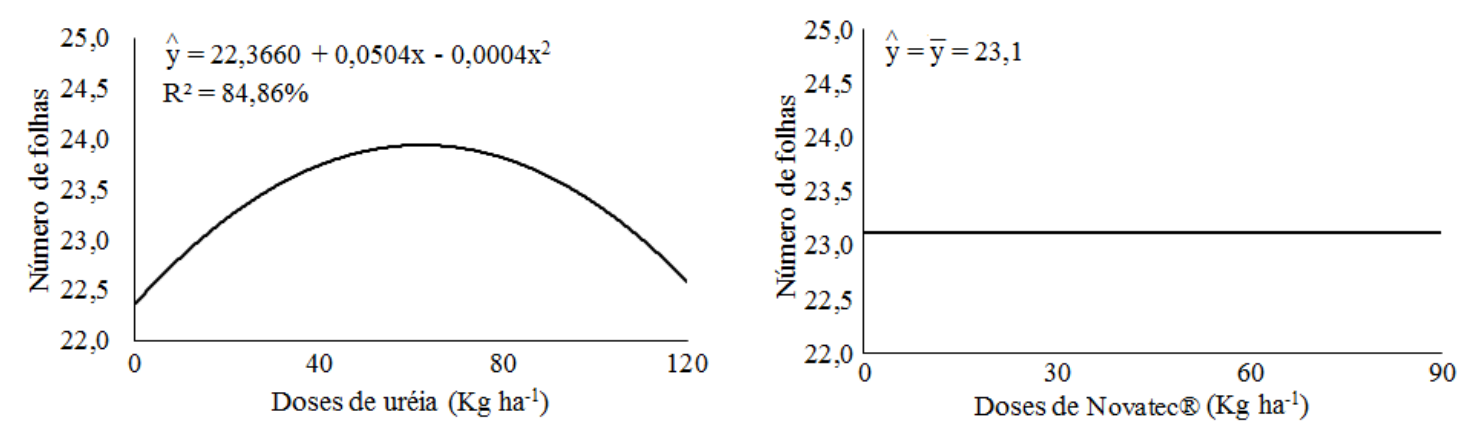

Figura 1. Número médio de folhas de alface americana cv. Lucy Brown em função das doses de a) ureia, b) $\operatorname{NovaTec}^{\circledR}$, Jataí-GO, 2013

O número de folhas é uma característica importante, principalmente pelo fato da alface ser uma hortaliça folhosa, cujas folhas constituem a parte comercial (FILGUEIRA, 2008) e também pelo fato de que o consumidor efetua a compra por unidade e não por peso, observando assim a aparência, volume e número de folhas por cabeça (DIAMANTE et al., 2013). Em alface, a maior quantidade de folhas por planta resulta, em geral, numa maior área foliar, maior massa fresca e, consequentemente, produtividade (ARAÚJO NETO et al., 2009).

Para o diâmetro do caule, foi verificado interação entre os fatores doses de ureia e doses de NovaTec ${ }^{\circledR}$. Realizando-se o desdobramento de doses de ureia dentro de cada nível de $\mathrm{NovaTec}^{\circledR}$, verificou-se que apenas as doses zero e $30,0 \mathrm{~kg} \mathrm{ha}^{-1}$ de NovaTec $^{\circledR} \quad$ proporcionaram efeitos significativos. Com a menor dose, obteve-se o maior diâmetro $(32,7 \mathrm{~mm})$ com a utilização de 57,8 $\mathrm{kg} \mathrm{ha}^{-1}$ de ureia. Já com a dose de $60,0 \mathrm{~kg} \mathrm{ha}^{-1}$ de NovaTec ${ }^{\circledR}$, o maior diâmetro de caule $(32,5 \mathrm{~mm})$ foi obtido com a aplicação de $36,7 \mathrm{~kg} \mathrm{ha}^{-1}$ de ureia (Figura 3a).

Santi et al. (2013) avaliando a aplicação de torta de filtro em três cultivares de alface americana também observaram comportamento quadrático para a variável diâmetro comercial da cabeça em função da aplicação de ureia, com diâmetro máximo de $1,9 \mathrm{~cm}$. Ressalta-se, de acordo com Mota et al. (2001), que a característica diâmetro do caule é de grande importância para a indústria de fast food, pois este é retirado manualmente para posterior fatiamento da cabeça da alface, quanto mais grosso é o caule mais rápido ele é retirado, aumentando o rendimento industrial.

Neste estudo, houve efeito significativo da interação entre doses de ureia e NovaTec ${ }^{\circledR}$ para o comprimento de caule. No desdobramento de doses de ureia 
dentro de cada dose de NovaTec ${ }^{\circledR}$, verificase que, com exceção da maior dose $(90 \mathrm{~kg}$ $\left.\mathrm{ha}^{-1}\right)$, as demais apresentaram diferenças estatísticas significativas, com efeito quadrático. Com a dose zero do produto $\mathrm{NovaTec}^{\circledR}$, o maior comprimento de caule $(6,6 \mathrm{~cm})$ foi obtida com a dose de $55,7 \mathrm{~kg} \mathrm{ha}^{-}$ ${ }^{1}$ de ureia. Com a dose de 30,0 $\mathrm{kg} \mathrm{ha}^{-1}$ de NovaTec $^{\circledR}$, o maior comprimento foi de 6,5 cm quando a dose de ureia aplicada foi de $101,4 \mathrm{~kg} \mathrm{ha}^{-1}$. Já com a dose de $60,0 \mathrm{~kg} \mathrm{ha}^{-1}$ obteve-se o comprimento máximo de $6,3 \mathrm{~cm}$ com o uso de 50,0 $\mathrm{kg} \mathrm{ha}^{-1}$ de ureia (Figura 2b).

O comprimento de caule é característica importante para a indústria, pois está diretamente relacionado ao rendimento da matéria-prima. O caule é descartado no momento do processamento, sendo assim, caules muito compridos, acima de 7,0 cm, representam perda de material e, consequentemente, diminuição no rendimento (YURI et al., 2004). O caule excessivamente comprido também acarreta menor compacidade da "cabeça" (RESENDE et al., 2003). O comprimento e o diâmetro do caule são duas características de relativa importância para a cultura da alface americana, uma vez que é indesejável um caule que apresente grandes proporções.

A massa fresca total e comercial evidenciou efeito quadrático para as doses de nitrogênio. Em relação à produção total, a produção máxima foi de $610 \mathrm{~g}$ planta $^{-1} \mathrm{com}$ a dose de $60 \mathrm{~kg} \mathrm{ha}^{-1}$ de ureia (Figura 3a) e de $600 \mathrm{~g} \mathrm{planta}^{-1}$ com a dose de $38,8 \mathrm{~kg} \mathrm{ha}^{-1}$ de NovaTec $^{\circledR}$ (Figura 3b). Já para a produção comercial de alface, obteve-se produção máxima de $500 \mathrm{~g}$ com a dose de $61 \mathrm{~kg} \mathrm{ha}^{-1}$ de ureia (Figura 3a) e de 470 g com a dose de $45 \mathrm{~kg} \mathrm{ha}^{-1}$ de NovaTec ${ }^{\circledR}$ (Figura 3b).

Resende et al. (2005), estudando doses de nitrogênio na cultivar Raider, obtiveram para massa fresca comercial no município de Três Pontas, MG que a dose de $89,1 \mathrm{~kg} \mathrm{ha}^{-1}$ de nitrogênio em cobertura propiciou a maior resposta, com 450,1 g planta $^{-1}$ de massa fresca comercial. Já em outro experimento, Resende et al. (2012), estudando doses de nitrogênio na cultivar Raider, obtiveram para massa fresca total e comercial, no outono, no município de Três Pontas, MG, os valores de 764,9 e 450,5 g planta $^{-1}$, respectivamente. 
a

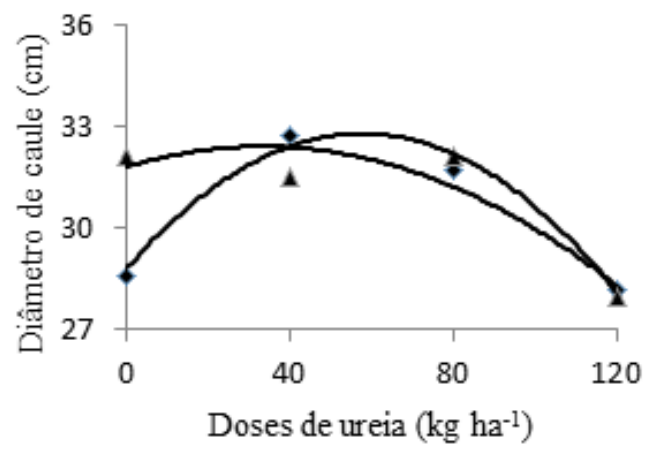

- $\left(0,0 \mathrm{~kg} \mathrm{ha}^{-1}\right.$ de NovaTec $\left.{ }^{2}\right) \mathrm{Y}=28,758+0,138 \mathrm{X}-0,0012 \mathrm{X}^{2} \mathrm{R}^{2}=0,97$

$\boldsymbol{\Delta}\left(60,0 \mathrm{~kg} \mathrm{ha}^{-1}\right.$ de NovaTec $\left.{ }^{2}\right) \mathrm{Y}=31,834+, 0036 \mathrm{X}-0,0005 \mathrm{X}^{2} \mathrm{R}^{2}=0,64$ $\mathrm{b}$

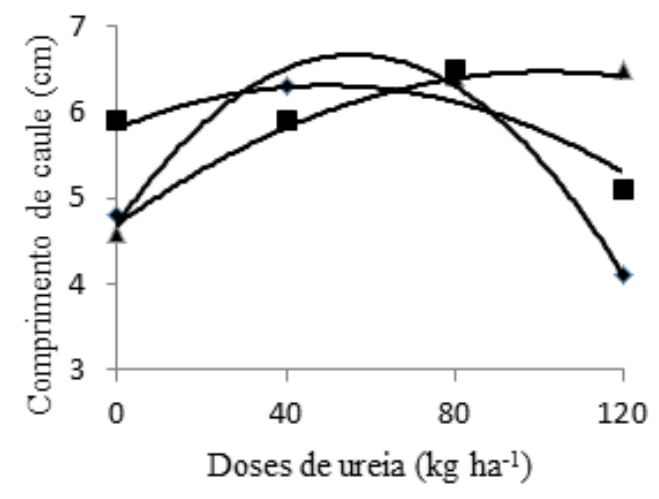

- $\left(0,0 \mathrm{~kg} \mathrm{ha}^{-1}\right.$ de NovaTec $\left.{ }^{2}\right) \mathrm{Y}=4,748+0,068 \mathrm{X}-0,0006 \mathrm{X}^{2} \quad \mathrm{R}^{2}=0,97$

- ( $\left(30,0 \mathrm{~kg} \mathrm{ha}^{-1}\right.$ de NovaTec $\left.{ }^{2}\right) \mathrm{Y}=4,692+0,036 \mathrm{X}-0,00017 \mathrm{X}^{2} \mathrm{R}^{2}=0,99$

\ $\left(60,0 \mathrm{~kg} \mathrm{ha}^{-1}\right.$ de NovaTec $\left.{ }^{2}\right) \mathrm{Y}=5,796+, 0020 \mathrm{X}-0,0002 \mathrm{X}^{2} \mathrm{R}^{2}=0,64$

Figura 2. Diâmetro de caule (a) e comprimento de caule (b) de alface americana, cv. Lucy Brown, em função das doses de ureia e de NovaTec ${ }^{\circledR}$, Jataí-GO, 2013
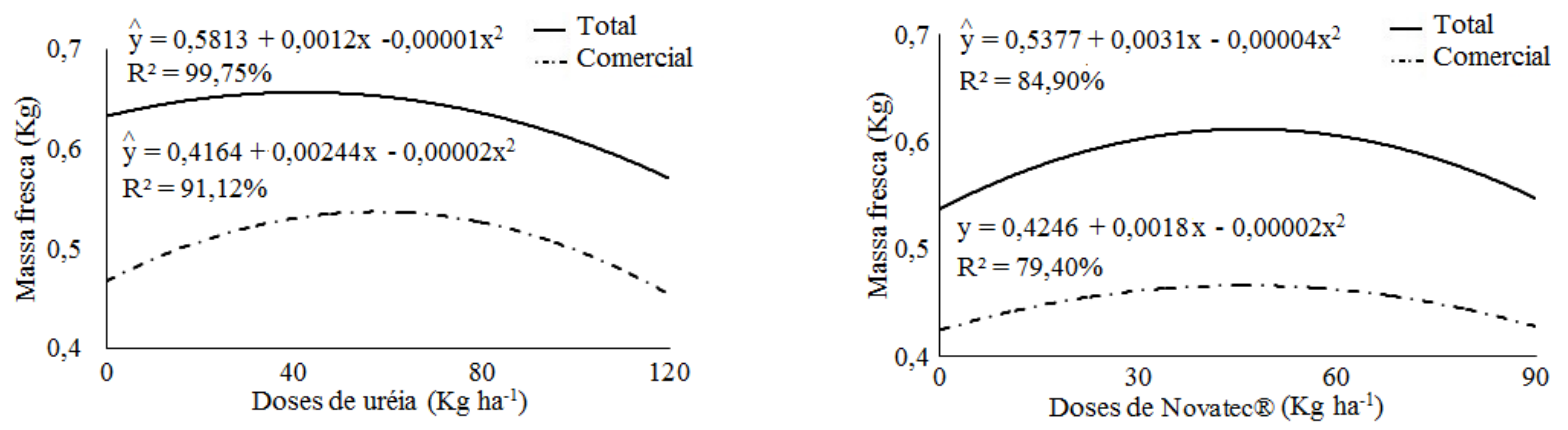

Figura 3. Massa fresca total e comercial (kg planta-1) alface americana cv. Lucy Brown em função das doses de a) ureia, b) NovaTec®, Jataí-GO, 2013

\section{CONCLUSÕES}

Todas as características avaliadas foram influenciadas pela adubação com ureia enquanto que NovaTec ${ }^{\circledR}$ influenciou apenas o comprimento do caule e as massas fresca total e comercial.

A maior massa fresca comercial foi obtida com a aplicação de $61 \mathrm{~kg} \mathrm{ha}^{-1}$ de ureia.
Assim, conclui-se que, nas condições de primavera do município de Jataí-GO, para a obtenção de elevadas produtividades, sem afetar a qualidade do produto comercial da alface americana 9cv. Lucy Brown), pode-se recomendar a dose de $60,0 \mathrm{~kg} \mathrm{ha}^{-1}$ de ureia ou 45,0 kg ha- ${ }^{-1}$ de NovaTec ${ }^{\circledR}$. Todavia, ressalta-se que são necessários trabalhos futuros realizando comparações quanto às 
questões referentes à viabilidade econômica

do uso de cada um dos produtos testados no

presente experimento.

\section{REFERÊNCIAS}

ALMEIDA, T. B. F.; PRADO, R. M.; CORREIRA, M. A. R.; PUGA, A. P.; BARBOSA, J. C. 2011. Avaliação nutricional da alface cultivada em soluções nutritivas suprimidas de macronutrientes.

Biotemas,

Florianópolis, 24, n. 2, p. 27-36.

ARAÚJO NETO, S. E.; FERREIRA, R. L. F.; PONTES, F. S. T. 2009. Rentabilidade da produção da orgânica de cultivares de alface com diferentes preparo de solo e ambiente de cultivo. Ciência Rural, Santa Maria, v. 39, n. 5, p. 1362-1368.

BENINNI, E. R. Y.; TAKAHASHI, H. W.; NEVES, C. S. V. J. 2005. Concentração e acúmulo de macronutrientes em alface cultivada em sistemas hidropônico e convencional. Semina: Ciências Agrárias, Londrina, v. 26, n. 3, p. 273282.

CASTRO, S. R. P.; FERRAZ JÚNIOR, A. S. L. 1998. Teores de nitrato nas folhas e produção da alface cultivada com diferentes fontes de nitrogênio. Horticultura Brasileira, Brasília, v.16, n.1, p.65-68.

DIAMANTE, M. S.; SANTINO JUNIOR, S.; INAGAKI, A. M.; SILVA, M. B.; DALLACORT, R. 2013. Produção e resistência ao pendoamento de alfaces tipo lisa cultivadas sob diferentes ambientes. Revista Ciência Agronômica, Fortaleza, v. 44, n.1, p. 133-140.

FERNANDES, H. S.; MARTINS, S. R. 1999. Cultivo de alface em solo em ambiente protegido. Informe Agropecuário, Belo Horizonte, v. 20, n. 200/201, p. 56-63.
FILGUEIRA, F. A. R. 2008. Manual de olericultura: cultura e comercialização de hortaliças. 3 ed. Viçosa: UFV. 421p.

GOTO, R.; GUIMARÃES, V. F; ECHER, M. M. 2001. Aspectos fisiológicos e nutricionais no crescimento e desenvolvimento de plantas hortícolas. In: FOLEGATTI, M. V.; CASARINI, E.; BLANCO, F. F.; BRASIL, R. P. C.; RESENDE, R. S. (Coord.) Fertirrigação: flores, frutas e hortaliças. Guaíba: Agropecuária, v.2, p.241-268.

INMET - INSTITUTO NACIONAL DE METEOROLOGIA. 2013a. BDMEP Banco de Dados Meteorológicos para Ensino e Pesquisa: Série Histórica Dados Diários de 01/01/1982 a 31/12/2012 Estação: 83464 - Jatai GO. Disponível em: <http://www.inmet.gov.br/portal/index.p $\mathrm{hp}$ ? $\mathrm{r}=\mathrm{bdmep} / \mathrm{bdmep}>$. Acesso em Dez. de 2013.

INMET - INSTITUTO NACIONAL DE METEOROLOGIA. 2013b. BDMEP Banco de Dados Meteorológicos para Ensino e Pesquisa: Série Histórica Dados Diários de 28/10/2013 a 04/12/2013 Estação: 83464 - Jatai GO. Disponível em: $<$ http://www.inmet.gov.br/portal/index.p hp? $\mathrm{r}=$ bdmep/bdmep $>$. Acesso em Fev. de 2014.

MALAVOLTA, E. 2006. Manual de nutrição mineral de plantas. São Paulo: Ceres. 638p

MOTA, J. H.; SOUZA, R. J. S.; SILVA, E. C.; CARVAlHO, J. G.; YURI, J. E. 2001. Efeito do cloreto de potássio via fertirrigação na produção de alfaceamericana em cultivo protegido. Ciência e Agrotecnologia, Lavras, v. 25, n. 3, p. 542-549.

RESENDE, G. M.; YURI, J. E.; MOTA, J. H.; SOUZA, R. J.; FREITAS, S. A. C.; RODRIGUES JÚNIOR, J. C. 2003. Efeitos de tipos de bandejas e idade de 
transplantio de mudas sobre o desenvolvimento e produtividade de alface americana. Horticultura

Brasileira, Brasília, v. 21, p. 562- 567.

RESENDE, G. M.; ALVARENGA, M. A. R.; YURI, J. E.; MOTA, J. H.; SOUZA, R. J.; RODRIGUES JUNIOR, J. C. 2005. Produtividade e qualidade pós-colheita da alface americana em função de doses de nitrogênio e molibdênio. Horticultura Brasileira, Brasília, v. 23, n. 4, p. 127 130.

RESENDE, G. M.; YURI, J. E.; MOTA, J. H. 2012. Épocas de plantio e doses de nitrogênio no rendimento e qualidade pós-colheita da alface americana. Horticultura Brasileira, Brasília, v. 30, n. 2, p. 6665-6672. (Suplemento - CD Rom).

SANTOS, H. G.; JACOMINE, P. K. T.; ANJOS, L. H. C.; OLIVEIRA, V. A.; OLIVEIRA, J. B.; COELHO. M. R.; LUMBRERAS, J. F.; CUNHA, T. J. F. (Ed.). 2006. Sistema brasileiro de classificação de solos. 2. ed. Rio de Janeiro: Embrapa Solos. 306p.

SANTI, A.; SCARAMUZZA, W. L. M. P.; NEUHAUS, A.; DALLACORT, R.; KRAUSE, W.; TIEPPO, R. C. 2013. Desempenho agronômico de alface americana fertilizada com torta de filtro em ambiente protegido. Horticultura Brasileira, Brasília, v. 31, n. 2, p. 338343.

YURI, J. E.; MOTA, J. H.; SOUZA, R. J.; RESENDE, G. M.; FREITAS, S. A. C.; RODRIGUES JUNIOR, J. C. 2002. Alface americana: cultivo comercial. Lavras: UFLA. 51p.

YURI, J. E.; RESENDE, G. M.; RODRIGUES JUNIOR, J. C.; MOTA, J. H.; SOUZA, R. J. 2004. Efeito de composto orgânico sobre a produção e características comerciais de alface americana. Horticultura Brasileira, Brasília, v. 22, n. 1, p. 127-130.
Recebido em: 18/9/2015

Aceito para publicação em: 28/7/2016 